\title{
Mutants of Aspergillus nidulans Impaired in Penicillin Biosynthesis
}

\author{
By G. F. ST L. EDWARDS AND G. HOLT \\ Bio-Organic Research Group, The Polytechnic of Central London, \\ London WIM 8JS \\ AND K. D. MACDONALD \\ Microbiological Research Establishment, Porton Down, Nr. Salisbury, Wiltshire
}

(Received 20 June 1974)

INTRODUCTION

Mutants blocked in the production of a metabolite can provide information on intermediate products in the biosynthetic pathway of that metabolite and the number of genetic loci involved. Lemke \& Nash (I972) have isolated mutant strains of Cephalosporium acremonium unable to yield $\beta$-lactam antibiotics and have reported on their ability to synthesize peptides implicated as intermediates in the elaboration of penicillin $\mathrm{N}$ and cephalosporin $\mathrm{C}$. Bonner (1947) isolated 55 mutants of Penicillium notatum which produced less than $10 \%$ of the normal amount of penicillin. Mixed cultures of all possible pairings of these mutants did not show normal penicillin production. Caglioti \& Sermonti (1956) and Sermonti (1956) examined nine mutants of Penicillium chrysogenum with much reduced or no detectable penicillin activity. Heterozygous diploid strains were synthesized between different mutants and in only one case did complementation occur. These results indicated the existence of two loci affecting penicillin production.

The work of Holt \& Macdonald (I968 $a, b$ ) and Macdonald, Holt \& Ditchburn (1972) on Aspergillus nidulans established a useful system for the genetic study of penicillin production. In this mould, although penicillin yields are low (Holt \& Macdonald, 1968a) the interpretation of crosses is easier than in $P$. chrysogenum. Work was therefore undertaken to produce mutants of $A$. nidulans impaired in penicillin biosynthesis for their use in complementation analyses. This communication reports the isolation of such mutants using a range of mutagens to avoid possible locus specificity.

\section{METHODS}

Organisms. Mutants, derived from Aspergillus nidulans, strain NRRL I94 (Pontecorvo, Roper, Hemmons, Macdonald \& Bufton, 1953) were kindly supplied by Dr A. J. Clutterbuck of the University of Glasgow. The domestic codes and phenotypes of the strains used are: G5 (biAr), G26 (biAr; w-oro), G30 (suAadE2o yA2 adE2o; acrAI; galAr; pyroA4; facA303; $s B_{3}$; nicB8; riboB2), G3I ( $\alpha$; galAr; pyroA4; facA303; sB3; nicB8; riboB2), GH8 (biAI; fwAI), GHI ( (yA2; pyroA4; cnxA5), GHI3 (biAI; niaDI7), and GH26 (biAI; methGI; w-0o5).

Genetic symbols. For genes determining: inability to utilize a specific sugar as sole carbon source - galAI $=$ galactose , nutritional requirements $-a d E 2 o=$ adenine, $b i A I=$ biotin, methGI = methionine, $n i c B 8=$ nicotinic acid, pyro $A 4=$ pyridoxine, $r i b o B 2=$ riboflavin; ability to suppress nutritional requirement - suAadE2o = suppressor of $a d E 20$; inability to utilize specific nitrogen compounds as sole nitrogen source - cnxA5 = nitrate and hypoxanthine, $\quad$ nia $D_{I 7}=$ nitrate; resistance $-\operatorname{acr} A I=$ acriflavine, $f a c A 303=$ fluoroacetate; 
Table I. Frequency of penicillinless mutants induced by different mutagens

\begin{tabular}{|c|c|c|c|c|}
\hline Strain & Mutagen & $\begin{array}{l}\text { No. of } \\
\text { isolates } \\
\text { screened }\end{array}$ & $\begin{array}{l}\text { No. of } \\
\text { isolates } \\
\text { selected }\end{array}$ & $\begin{array}{c}\text { Frequency } \\
\text { of peni- } \\
\text { cillinless } \\
\text { mutants }(\%)\end{array}$ \\
\hline G5 & FUV & 500 & I & ) \\
\hline G30 & FUV & 1000 & 2 & 0.19 \\
\hline G3 I & FUV & I 200 & 2 & - \\
\hline G26 & NTG & 4100 & 3 & 0.07 \\
\hline GH8 & EMS & 4900 & 5 & 0.10 \\
\hline GHI I & GC & I 600 & 10 & 0.63 \\
\hline GHI 3 & 8MOP & 5200 & 4 & 0.08 \\
\hline \multirow[t]{2}{*}{ GH26 } & NA & I 400 & I & 0.07 \\
\hline & & I9900 & Total 28 & Mean 0.14 \\
\hline
\end{tabular}

mutant spore colour $-f w A I=$ fawn, $w$-oro and $w$-0o5 $=$ white, $y A 2=$ yellow. The symbol $\alpha$ indicates that the strain may also carry suAadEzo.

Media. Minimal medium (MM) and complete medium (CM) were based on those described by Pontecorvo et al. (1953) The fermentation medium (FM) for penicillin production was that used by Holt \& Macdonald (I968a).

Production of mutants. The mutagens employed and references to the details of the methods used were as follows: far-u.v. light, FUV (Macdonald, Hutchinson \& Gillett, 1963); $N$-methyl- $N^{\prime}$-nitro- $N$-nitrosoguanidine, NTG (Martinelli \& Clutterbuck, 197I); ethyl methane sulphonate, EMS (Yost \& Chaleff, 1967 ); gamma rays from a ${ }^{60} \mathrm{Co}$ source, GC (Alderson \& Scott, I97I ; the irradiation unit described by Burlin \& Chan, 197I, was used); near-u.v. light in the presence of 8-methoxypsoralen, 8MOP (Alderson \& Scott, 1970); nitrous acid, NA (Siddiqui, 1962).

A rapid screening method for the isolation of mutants impaired in penicillin synthesis. After mutagenic treatment conidia were plated on CM agar and those surviving gave rise to individual colonies. One loopful of conidia from each colony was inoculated into $2 \mathrm{~cm}^{3}$ of FM contained in a screw-cap Universal bottle of $28.4 \mathrm{~cm}^{3}$ ( $\mathrm{I} \mathrm{oz}$ ) capacity. After static incubation for 5 days at $25^{\circ} \mathrm{C}$ a single drop of the culture medium was spotted on the surface of a test agar seeded with spores of Bacillus subtilis. Following overnight incubation of the assay plate at $37^{\circ} \mathrm{C}$, single colony isolates which gave no inhibition zones were selected as putative mutants unable to synthesize penicillin. All were subsequently grown in submerged shaken cultures and their penicillin yields assayed (Holt \& Macdonald, 1968a).

\section{RESULTS AND DISCUSSION}

All of the parent strains used in this investigation yielded 2 to $3 \mu \mathrm{g}$ penicillin $/ \mathrm{cm}^{3}$. After growth in submerged culture, mutant isolates were classified as 'penicillinless' when they gave titres of no more than $10 \%$ that of the strains from which they were derived. The frequency of mutants selected after different mutagenic treatments is shown in Table $I$. Although the mutations were induced in different strains and hence in different genetic backgrounds, it can be seen that ${ }^{60} \mathrm{Co} \gamma$-irradiation gave the highest frequency of penicillinless mutants. Das \& Nandi (1972) compared a number of mutagens including FUV and GC. for their efficiency in producing mutants of Aspergillus niger with altered citric acid production. The most effective mutagen was GC. Gamma irradiation induces a high frequency of chromosomal aberrations in A. nidulans (Kafer \& Chen, 1964). It is of interest that five of 
the ten mutants induced by GC treatment in this experiment were morphologically different from the parent strain, GHI I, when grown on surface culture.

Using standard genetic methods (Pontecorvo et al. 1953), diploid complementation tests were made between selected pairs of mutants, establishing that 20 of the 28 penicillinless mutants selected belonged to a single complementation group and that the remaining eight were representatives of at least four other complementation groups. All penicillinless mutants retaining normal morphology after treatment with the mutagens employed were members of one complementation group, designated npe A. Haploidization analysis (McCully $\&$ Forbes, 1965) enabled the locus npe $A$ to be assigned to linkage group $V_{I}$ in $A$. nidulans.

These results show that the situation in $A$. nidulans with respect to mutations leading to impaired penicillin biosynthesis is similar to that found by Sermonti (1956) in Penicillium chrysogenum in that most of these are within a single cistron. However, in $A$. nidulans at least four other loci affecting penicillin production in some way have now been identified.

\section{REFERENCES}

Alderson, T. \& SCOTT, B. R. (1970). The photosensitizing effect of 8-methoxypsoralen on the inactivation and mutation of Aspergillus conidia by near ultraviolet light. Mutation Research 9, 569-578.

Alderson, T. \& ScotT, B. R. (197I). Induction of mutations by $\gamma$-irradiation in the presence of oxygen or nitrogen. Nature New Biology 230, 45-48.

Bonner, D. (1947). Studies on the biosynthesis of penicillin. Archives of Biochemistry 13, I-9.

Burlin, T. E. \& ChAN, F. K. (I97I). Physical measurements on a ${ }^{60} \mathrm{Co}$ irradiation unit. International Journal of Applied Radiation and Isotopes 22, 73-83.

Caglioti, M. T. \& Sermonti, G. (1956). A study of the genetics of penicillin-producing capacity in Penicillium chrysogenum. Journal of General Microbiology 14, 38-46.

Das, A. \& NANDI, P. (1972). Specific effects of mutagens on Aspergillus niger producing citric acid. Folia microbiologica (Praha) 17, 248-250.

Holt, G. \& Macdonald, K. D. (I968a). Penicillin production and its mode of inheritance in Aspergillus nidulans. Antonie van Leeuwenhoek 34, 409-416.

Holt, G. \& Macdonald, K. D. (1968 $b$ ). Isolation of strains with increased penicillin yield after hybridization in Aspergillus nidulans. Nature, London 219, 636-637.

KAFER, E. \& ChEN, T. L. (1964). Translocations and recessive lethals induced in Aspergillus by ultra-violet light and gamma rays. Canadian Journal of Genetics and Cytology 6, 249-254.

LEMKE, P. A. \& NASH, C. H. (1972). Mutations that affect antibiotic synthesis by Cephalosporium acremonium. Canadian Journal of Microbiology 18, 255-259.

Macdonald, K. D., Holt, G. \& Ditchburn, P. (I972). The genetics of penicillin production. In Fermentation Technology Today, Proceedings IV International Fermentation Symposium, pp. 25I-257. Edited by G. Terui. Japan: Society of Fermentation Technology.

Macdonald, K. D., Hutchinson, J. M. \& Gillett, W. A. (1963). Isolation of auxotrophs of Penicillium chrysogenum and their penicillin yields. Journal of General Microbiology 33, 365-374.

MCCully, K.S. \& Forbes, E. (1965). The use of $\beta$-fluorophenylalanine with 'master strains' of Aspergillus nidulans for assigning genes to linkage groups. Genetical Research 6, 352-359.

Martinelli, S. D. \& Clutterbuck, A. J. (I97I). A quantitative survey of conidiation mutants in Aspergillus nidulans. Journal of General Microbiology 69, 26I-268.

Pontecorvo, G., Roper, J. A., Hemmons, L. M., Macdonald, K. D. \& Bufton, A. W. J. (I953). The genetics of Aspergillus nidulans. Advances in Genetics 5, 14I-238.

SERMONTI, G. (1956). Complementary genes which affect penicillin yields. Journal of General Microbiology I5, $599-608$.

SIDDIQUI, O. H. (1962). Mutagenic action of nitrous acid on Aspergillus nidulans. Genetical Research 3 , 303-314.

Yost, H. T. \& ChalefF, R, S. (1967). Induction of mitotic recombination in Saccharomyces cerevisiae by ethylmethane sulphonate. aNture, London 215, 660-66I. 